\title{
Creating a Virtual World for Mathematics
}

\author{
Young Rae Kim ${ }^{1}$, Mi Sun Park ${ }^{1}$ \\ ${ }^{1}$ Department of Curriculum and Instruction, College of Education and Human Development, Texas A\&M University-San \\ Antonio, Texas, United States \\ Correspondence: Young Rae Kim, Department of Curriculum and Instruction, College of Education and Human \\ Development, Texas A\&M University-San Antonio, One University Way, San Antonio, TX 78224, United States.
}

\author{
Received: September 3, 2018 \\ Accepted: October 24, $2018 \quad$ Online Published: October 29, 2018 \\ doi:10.11114/jets.v6i12.3601 \\ URL: https://doi.org/10.11114/jets.v6i12.3601
}

\begin{abstract}
A virtual world was created using the popular sandbox game Minecraft to support the development of preservice teachers' knowledge for teaching mathematics. Preservice teachers explored the virtual world for a geometry activity involving area and volume problems. They then discussed how this integration of technology could support students' effective learning of mathematics in a meaningful way. The findings of the study demonstrated that to a certain extent the Minecraft activity supported the transfer of knowledge from preservice teachers' mathematics content knowledge to their mathematics pedagogical and instructional practice knowledge. Preservice teachers appreciated the usefulness and effectiveness of the Minecraft activity in enhancing the teaching and learning of mathematics by visualizing mathematical concepts in the virtual world. This integration of technology also gave them an opportunity for professional growth. Although this study focuses on preservice teachers' perspectives on the Minecraft activity, the technology integration using Minecraft will also be beneficial for students because it engages them in active and discovery learning.
\end{abstract}

Keywords: area, volume, virtual world, Minecraft, technology integration, preservice teachers

\section{Introduction}

"Ooh, I can see the concept!" "Awesome! That's a great activity." These were frequent reactions of many K-8 preservice teachers in our mathematics methods courses when they explored integrating a popular sandbox game: Minecraft.

Technology is nothing new for students; it is everywhere in their lives. As a result of the easy access to various mobile devices, such smartphones and tablets, and their applications for entertainment, especially, digital games are popular leisure activities for most children including even under 8 years old young children (Gee, 2004; Judge, Floyd, \& Jeffs, 2015). Recently, teaching with technology has dramatically increased in our schools. The use of technology in classrooms is motivating students and providing more effective learning. (Burns \& Hamm, 2011; CCSSI, 2010; NCTM, 2014; Sung \& Hwang, 2013). Many educators have also been interested in using digital games as instructional tools to improve student learning through enhancing learning interest and motivation (Chan et al., 2017; Groff, Howells, \& Cranmer, 2010; Groff, McCall, Darvasi, \& Gilbert, 2015; Hsu, Tsai, Chang, \& Liang, 2017).

Yet it is important to use technology to meaningfully address students' learning goals, rather than for the sake of technology itself (Silverstein, Frechtling, \& Miyoaka, 2000) and for simply increasing student pleasure (Cordova \& Lepper, 1993). In mathematics classes, students should be occupied with learning mathematics, neither technology nor only pleasure. Teachers are required to become comfortable and familiar with technology by using it as an instructional tool to increase student mathematical reasoning and sense making in supporting student learning in mathematics (AMTE, 2017; NCTM, 2000). Thus, the use of technology is considered not only as the knowledge for what well-prepared preservice mathematics teachers should develop, but also ultimately, as an indicator for effective mathematics teacher preparation programs (AMTE, 2017; Moyer-Packenham, Niezgoda, \& Stanley, 2005).

In this article, we demonstrate the use of technology in mathematics methods courses for preservice teachers by using a sandbox game called Minecraft, which can be played on various electronic devices, such as the iPad, tablet, smart-phone, or computer. The purpose of this study was to investigate the experiences of preservice teachers in using Minecraft as an instructional tool. We were interested in examining the extent to which math activities using Minecraft 
might facilitate transfer knowledge from mathematics content knowledge to mathematics pedagogical and instructional practice knowledge.

We created a virtual world for mathematics, using Minecraft to develop our subjects' knowledge for teaching mathematics. Preservice teachers explored the virtual world for a geometry activity involving area and volume problems. Although the geometry activity presented here was used with preservice teachers in developing their ability to interpret students' thinking and knowledge of how to effectively transfer mathematics concepts in the way of facilitating student learning, it can also be implemented with students in the context of engaging them in active and discovery learning.

\section{Educational Use of Digital Games}

Most recently, Papadakis (2018) reviewed the literature regarding the use of digital games (e.g., video games or computer games) in classroom environments. Integrating technology with digital games has been supported as an effective instructional strategy based on various benefits in the educational process. In particular, many educators and researchers advocate that the use of digital games in education can motivate and improve student interest in learning (Chan et al., 2017; Groff et al., 2010; Groff et al., 2015; Hsu et al., 2017; Sung, Hwang, Lin, \& Hong, 2017). The educational use of digital games can engage students in the robust activity of student-centered learning and active learning by doing themselves (Gee, 2007; Gros, 2007; Ke, 2008; Lacasa, 2013; Prensky, 2007; Rideout \& Saphir, 2013). Digital games can work as an alternative representation for educational content (Protopsaltis, Panesse, Pappa, \& Hetzner, 2011) and differentiate instructions by providing a right learning environment for students having different academic backgrounds, but working together to meet a common learning goal. For example, in an interactive and stimulating learning environment, students who struggle with educational content can use a trial and error approach and progress at their own pace in learning through failure without any strong concern (Cruz, Carvalho, \& Araújo, 2016; Papanastasiou, Drigas, \& Skianis, 2017) while advanced students can be given a higher challenge level of tasks in the same learning environment (Hansen \& Storjord, 2016). Many educators and researchers also argue that the use of digital games in education can promote the development of not only students' conceptual understanding of concepts but also their lifelong learning skills, such as strategic thinking, logical and critical thinking, problem-solving, creativity, negotiating, group decision-making, collaboration, and communication skills (Bellotti, Berta, Gloria, \& Primavera, 2009; Groff et al., 2010; Gros, 2007; Ke, 2008; Kirriemuir \& McFarlane, 2004; McFarlane, Sparrowhawk, \& Heald, 2002).

In spite of these benefits described above, integrating technology with digital games is not widely adopted in education (Huizenga, Ten Dam, Voogt, \& Admiraal, 2017). Papadakis (2018) summarized several barriers causing the slow adoption of digital games in education. First, there are physical circumstances that interfere with integrating technology or adopting digital games in classes, such as the expense of technology integration with digital games and the lack of technical support (De Grove, Bourgonjon, \& Van Looy, 2012; Justice \& Ritzhaupt, 2015; Nancy \& Roberta, 2009; Rice, 2007a; Van Eck, 2006). A mismatch of digital games within a formal school system also causes several barriers to their use in schools, for example, curriculum and content mismatch, time limit within a school curriculum, and mismatch of learning objectives (McFarlane et al., 2002; Nancy \& Roberta, 2009; Rice, 2007b). Last but not least, several obstacles to the use of digital games in education stem from teachers playing the dominant role in a formal education. The most frequent barriers are negative teacher perceptions towards technology integration, especially the use of digital games for teaching and learning (Huizenga et al., 2017). The lack of teachers' experience and knowledge about how to utilize digital games as instructional tools also negatively affect the potential use of technology and digital games in their teaching (Groff et al., 2015; Hsu et al., 2017; Justice \& Ritzhaupt, 2015; Papadakis, 2018).

The recently rapid proliferation of mobile devices and applications for them and the increased interest in more active and student-centered learning within a formal education context (e.g., CCSSI, 2010; NCTM, 2014) might be able to address a considerable extent of the physical barriers and the mismatches to the use of digital games in education (Cruz et al., 2016; Papadakis, 2018; Papadakis \& Kalogiannakis, 2017). Research has also shown that the use of technology or digital games in teacher education positively affects not only preservice teachers' perceptions of its value as instructional tools and strategies but also the development of their knowledge for teaching (Nancy \& Roberta, 2009; Sonja, 2016).

Addressing the need for the use of technology in mathematics teacher preparation programs (AMTE, 2017; Moyer-Packenham et al., 2005) and the obstacles described above, we have designed problem-solving activities in a digital game context for preservice teachers in mathematics methods courses. First, the free version of Minecraft has been used to create a virtual world for mathematics. As mentioned earlier, Minecraft can also be played on various devices without any special training, and thus without any significant loss of time learning how to play the game. Only a few minutes of practicing can make participants ready to engage in the problem-solving tasks. Second, the topic of the 
geometry concepts, area and volume, has been chosen for a curriculum content match within a formal math class. This technology integration with Minecraft is intended to provide preservice teachers with an exemplar of how they can use a digital game and what to use it for in teaching mathematics. It also expects to enhance preservice teachers' knowledge for teaching mathematics by promoting the transfer of their knowledge from content knowledge to pedagogical and instructional practice knowledge.

The current study explores 1) preservice teachers' experience and perceptions on/towards the use of Minecraft for teaching and learning mathematics and 2) the extent to which the technology integration with Minecraft might facilitate transfer preservice teachers' knowledge from mathematics content knowledge to mathematics pedagogical and instructional practice knowledge.

\subsection{Minecraft: A 3D Block Virtual World}

Minecraft is a popular sandbox video game (sold over 100 million copies worldwide) where players dig (mine) and build (craft) whatever they want. The virtual world created by Minecraft is a 3D block world in which one can travel and build freely. Players use different stones/blocks, which are unit cubes with six unit square faces, to build any shapes. Minecraft has already been in use as an educational tool for various topics all over the world (Minecraft Teachers, 2015; Short, 2012). Educators have found several beneficial characteristics of Minecraft when used as a teaching tool in diverse educational fields, including mathematics. (Bos, Wilder, Cook, \& O'Donnell 2014). For example, blocks can be arranged such that they reproduce almost any static object or shape, thus providing stimuli for a wide range of education or research projects.

Multiplayers in Minecraft can also interact and communicate with one another in a single virtual world. When a single virtual world is built, there are several modes to choose from, such as 1) a creative mode in which players have unlimited building materials and the ability to fly, 2) an adventure mode in which players can explore custom maps created by other players, and 3) a spectator mode in which players can fly around blocks, but cannot place or destroy any.

For this study, we created a single virtual world for a geometry activity in Minecraft. Preservice teachers worked on a creative mode in the single world where we had set up various missions for them to complete. Meanwhile, the instructor as a spectator could observe the preservice teachers working in the virtual world.

\subsection{Minecraft Activity for Geometry}

Area and volume are important concepts when describing and comparing the size of objects in children's everyday lives. In addition, leading to the common area and volume formulas is critical to developing mathematical reasoning. These concepts provide children with an opportunity to observe how geometric ideas are connected and generalized in symbolic representation. This connection illustrates a link between geometry and algebra. Technology allows us to effectively visualize these concepts and processes.

We developed this geometry activity to help preservice teachers improve their interpretation ability of students' mathematical thinking and their transformation skills in enhancing students' understanding of the definitions of area and volume and the common area and volume formulas by visualizing these concepts in Minecraft.

We anticipated that the Minecraft activity would support the teaching and learning of area and volume because students could visualize the concepts while engaging in the 3D block virtual world. We adopted the following definitions:

1) The area of a two-dimensional shape is a measure of the amount of space inside the shape, and thus it is measured by counting unit squares to cover the shape without overlaps or gaps (CCSSI, 2010).

2) The volume of a three-dimensional shape is a measure of the amount of space inside the shape, and thus it is measured by counting unit cubes to fill the shape without overlaps or gaps (CCSSI, 2010).

The geometry activity is designed as a competition activity with multiplayers. There are two missions-finding 1) Area: how many blocks/stones are needed to cover the 2D shapes without overlaps or gaps and 2) Volume: how many blocks/stones are needed to create the 3D shapes without overlaps or gaps. Each 2D or 3D shape is placed in a spot separated by roads in the Minecraft world (see Figure 1). 

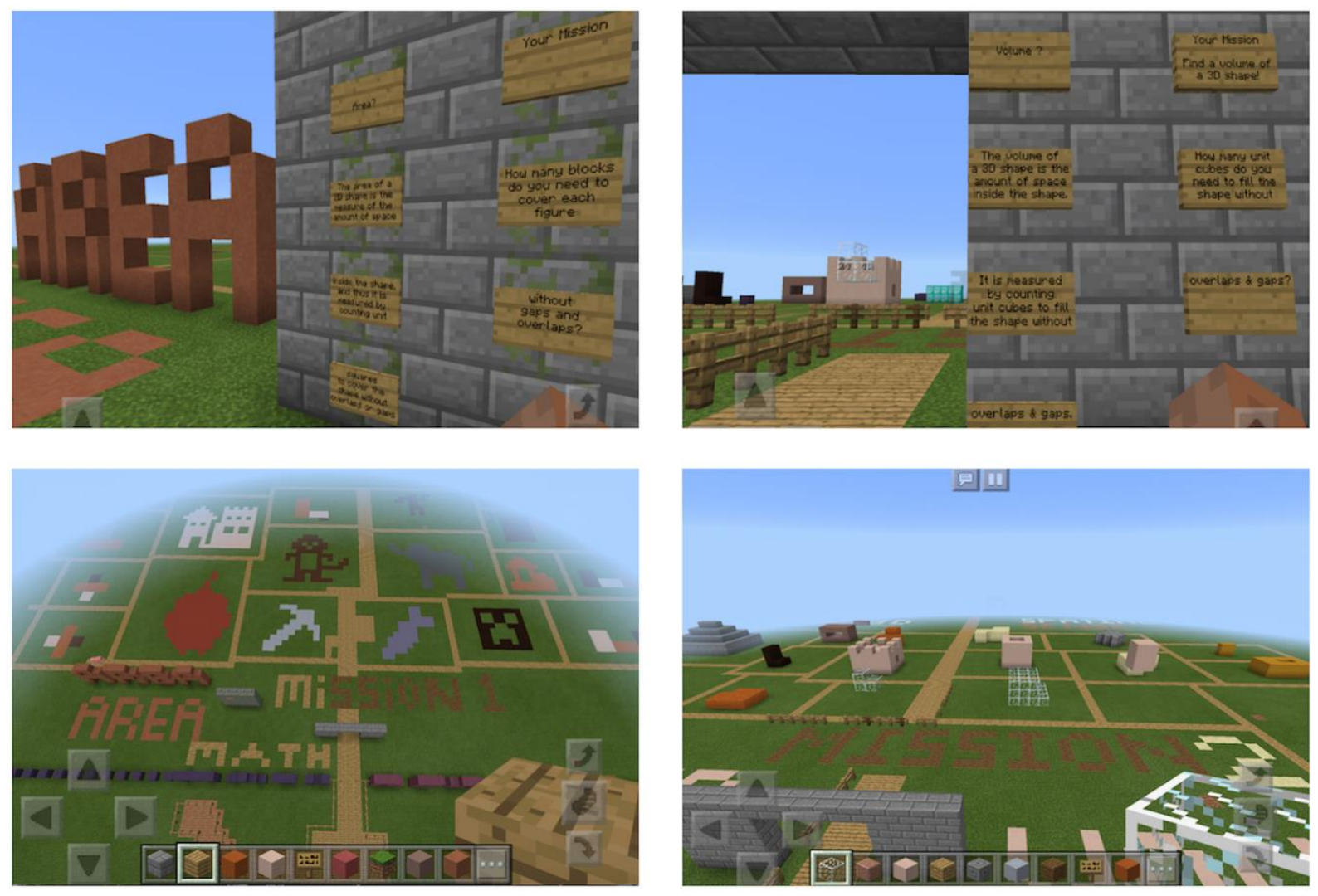

Figure 1. Mission 1-Area \& Mission 2-Volume

Multiplayers go to each spot and compete to put up signs with their answers-the areas or volumes of the given shapes. The player who puts the highest number of signs up with correct answers is the winner. A player can put up a sign regardless of how many signs exist in a given location if she/he thinks they are incorrect (see Figure 2). Only the first correct answer will be counted.

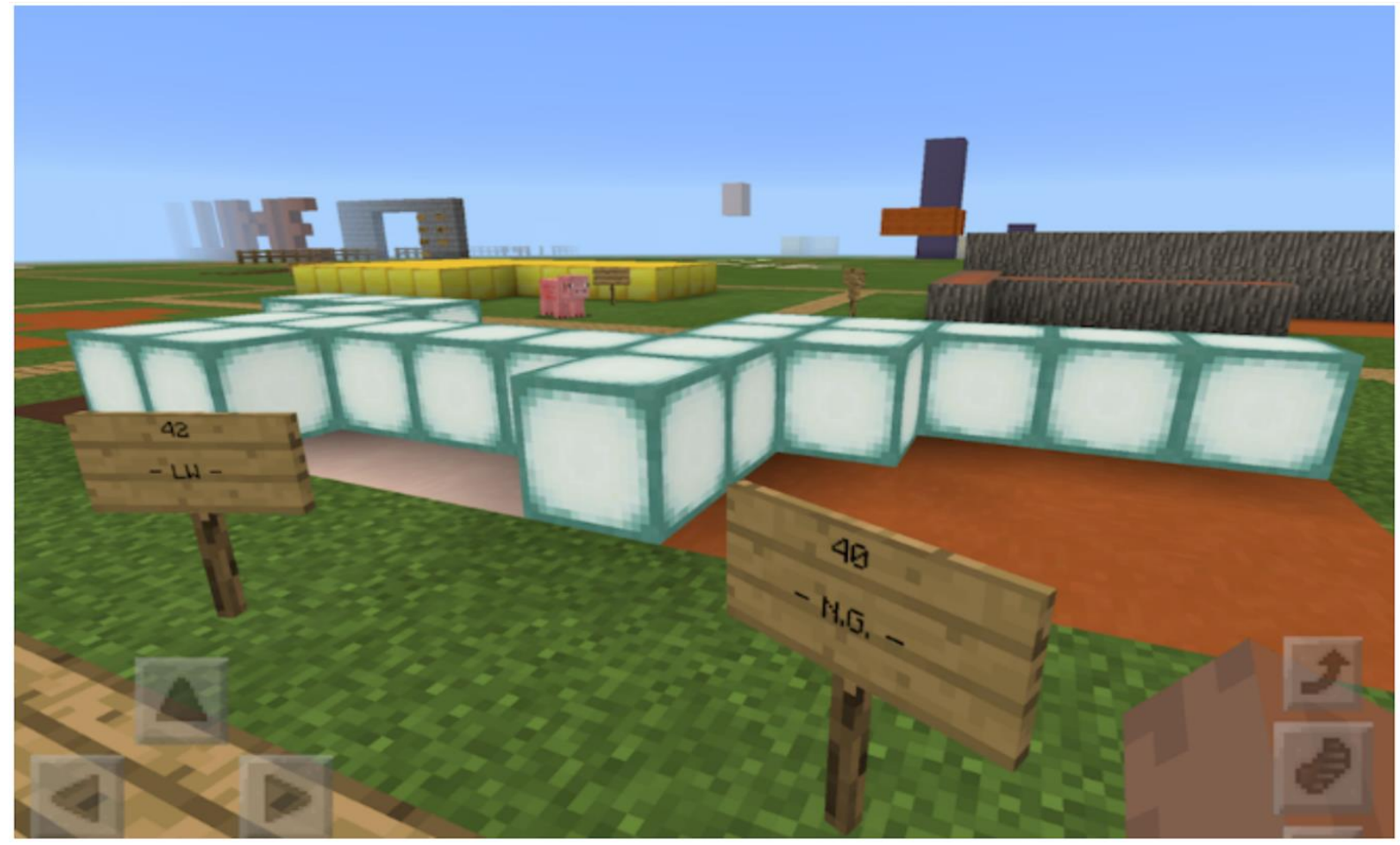

Figure 2. Samples of students' answers 
Players can see and count the unit blocks forming each shape by having their avatars touch the shape as outlines of unit square faces appear. Otherwise, each original shape can be rebuilt using blocks with outlines to show unit square faces. When we designed the activity, we intentionally chose blocks that had no outlines separating each unit square face. We anticipated players choosing their own ways to figure out the areas or volumes and ultimately inventing their own formulas.

\section{Method}

The current study adopted a case study approach and generated qualitative data to investigate preservice teachers' experiences and development of knowledge for teaching mathematics in using Minecraft. The descriptive, inductive and naturalistic characteristics of the study exploring the participants' experience and thinking while working within a group or an entire class in a natural classroom setting meet the needs of a case study and qualitative research methodology (Bogdan \& Biklen, 2003; Creswell, 2013). To explore the complexity of a case, we used multiple sources of data including audio transcripts, participants' work samples and journal reflections, and observational field notes collected during a mathematics methods class. In addition to this data triangulation using multiple sources, multiple researcher analysis was employed to establish rigor and credibility for the study (Creswell, 2013; Rallis \& Rossman, 2012; Yin, 2013).

\subsection{Participants}

The participants of this study included 48 preservice teachers attending math methods courses in a teacher preparation program in the United States. All of the participants in the study were at the third or last year of their teacher preparation program.

\subsection{Data Collection and Analysis}

The Minecraft activity was implemented with 48 preservice teachers in mathematics methods courses. They completed the two missions (Mission 1-Area \& Mission 2-Volume) in pairs. Two preservice teachers took turns controlling their avatar while working together on the competition. The players could find the mission statements at the entrances of the virtual world. They could also find a question prompting them to complete each mission near the entrances (see Figure 1 above). Some needed to practice controlling the Minecraft avatars because they had never played the game before. However, they grew accustomed to controlling their avatars very quickly, so they could begin the activity after a few minutes of practicing.

The instructor joined the virtual world as an observer. She monitored what her students were doing and what strategies they used to find the areas and volumes of the shapes. The preservice teachers were also encouraged to observe one another's work, assuming that their peers were their students. The observation allowed the instructor and the preservice teachers to explore the participants' thinking and potential misconceptions.

The preservice teachers then discussed how the integration of technology using Minecraft could support students' effective learning of mathematics in a meaningful way. Finally, the preservice teachers created their own rectangular prisms with a given volume and compared them. When comparing the shapes, they were expected to make connections between mathematical ideas.

The primary sources of data for this study were transcripts of the participants' discourse that was audio-recorded, the participants' work samples and journal reflections, and researcher field notes. The data were analyzed by combining both selective and open coding strategies (Creswell, 2013; Corbin \& Strauss, 2008; Miles \& Huberman, 1994) in order to identify and describe the preservice teachers' performances and reflections on the Minecraft activity. Both authors of this paper independently reviewed and carefully coded the data. Some preset categories, such as negative perception (NP), positive perception (PP), and transfer from content to pedagogical and instructional practice (TF), were used first for data analysis. Then, several new categories were added with a consensus from both of the authors as they become apparent within the data, such as misconception (MC), only content knowledge (OC), only pedagogical practice knowledge (OP), and math-focused instructional practice knowledge (MP). Any discrepancies from the authors were also resolved via mutual agreement through several meetings.

The results presented below are reorganized from the categories. They are not selective but focusing on the participants' transfer knowledge from mathematics content to mathematics pedagogical and instructional practice and their perceptions towards the use of Minecraft in teaching and learning mathematics. The results are also stated in the chronological order of the participants' learning activities in order to provide enough contextual information and thus describe the participants' experience and knowledge development in depth and in its natural context. 


\section{Results and Discussion}

\subsection{Preservice Teachers' Knowledge Development of Student Learning}

Most preservice teachers first covered the 2D shapes on the floor, using blocks/stones that had outlines separating each unit square face. Then they counted out the unit squares to find the areas of the shapes (see Figure 3). In finding rectangle areas, several only covered the edges of the rectangles and multiplied the numbers of the unit blocks covering the edges (e.g., $3 \times 7=21$ ). This strategy resulted in a connection between geometry and algebra leading to the common area formula (i.e., Base $\times$ Height). A couple of players counted out the unit blocks forming each shape based on the outlines of unit squares that appear when touching the shape.
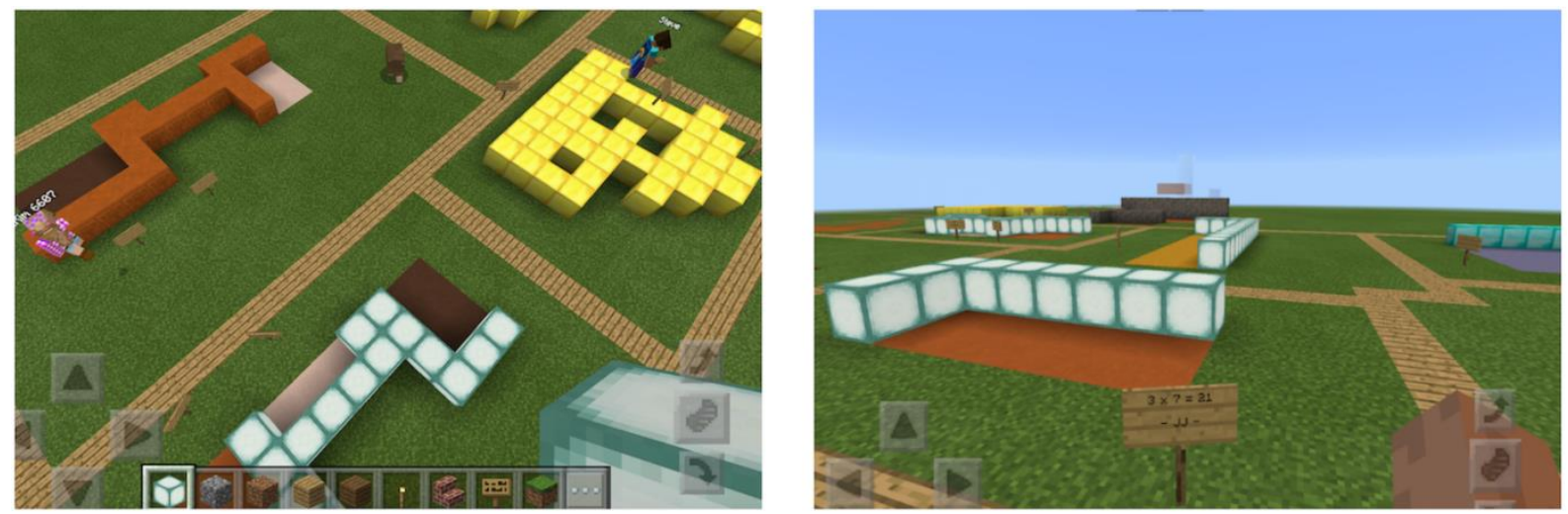

Figure 3. Samples of students' work for Mission 1-Area

On the other hand, in finding volumes, many preservice teachers first tried to count out the outlined unit blocks appearing when their avatars touched the shapes. Yet it was not easy for them to count all of the unit blocks, especially inside the space of the shapes. They often controlled their views of shapes by flying or moving their avatars. They then tried to build replica shapes beside the original shapes by using blocks/stones that had outlines separating each unit block (see Figure 4). To find the volume of a rectangular prism, several preservice teachers only built three edges of the shape. This strategy was similar to that which they used to find the area of a rectangle. They then multiplied the numbers of unit blocks covering the three edges (e.g., $3 \times 5 \times 2=30$ ). Their reasoning led to the common volume formula by connecting geometry and algebra (i.e., Length $\times$ Width $\times$ Height).

The visualization of area and volume in Minecraft provided preservice teachers with opportunities to develop their understanding of the concepts through not only focusing on the definitions of area and volume but also making connections between geometric concepts and algebraic concepts during the problem solving. These opportunities also allowed preservice teachers to develop their knowledge of how students would learn the mathematical concepts through problem solving, using and connecting multiple representations, and making connections among mathematical ideas that are emphasized as effective teaching practices (AMTE, 2017; NCTM, 2000, 2014). This knowledge development of student learning was further supported by preservice teachers' comments and reflections in the following sections.
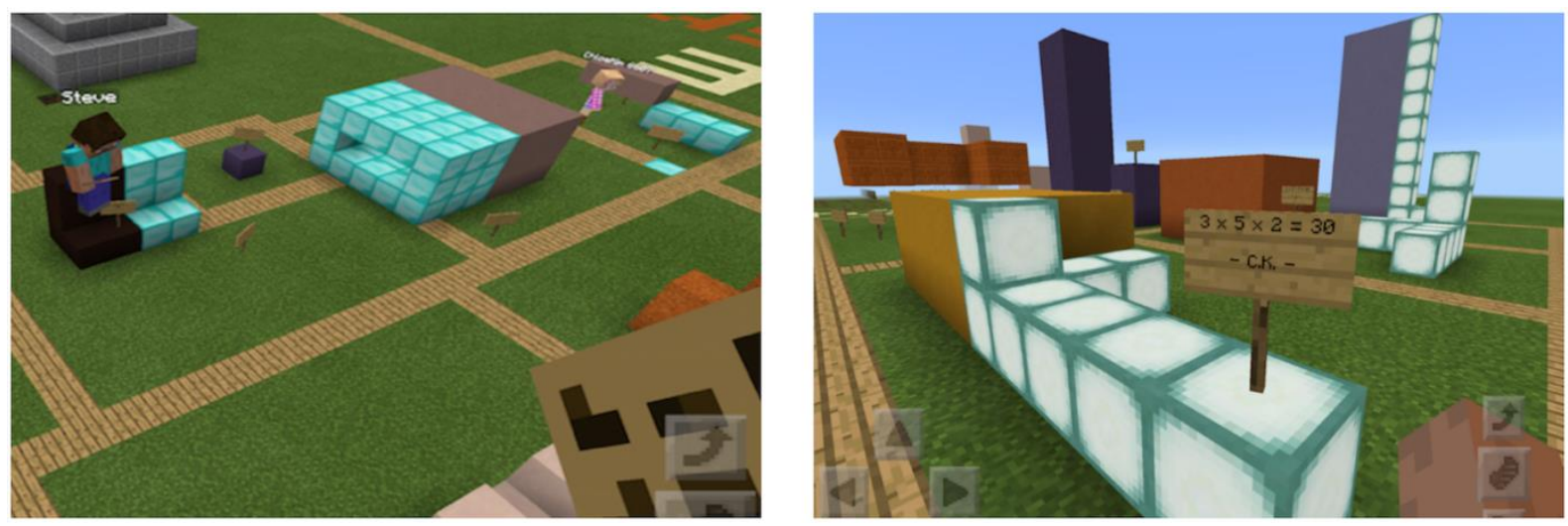

Figure 4. Samples of students' work for Mission 2-Volume

\subsection{Preservice Teachers' Transfer Knowledge from Content to Pedagogical and Instructional Practice}

As mentioned before, preservice teachers were required to assume that their peers were their students and to monitor 
one another's work while participating in the problem-solving tasks. During the activity, preservice teachers started spontaneous conversations about the concepts of area and volume in pairs or with their neighboring peers. For example, one preservice teacher didn't cover some of the spaces on a shape and counted the blocks without considering the gaps. The partner reminded her of the definition of area: "Hey, you didn't cover four blocks on the figure. I did. I got this." Meaningful conversations among participants were inspired throughout the activities: "The area is 56 square units, not cubic units. I mean you couldn't say unit blocks"; "Yes, it is on the floor. It's 2D"; "We need unit squares, not blocks"; "I don't care. The one face is a unit square" and so on.

In particular, preservice teachers were concerned about the treatment of area and 2D shapes in Minecraft as shown in the comments above. They argued that while some students could understand the one-to-one correspondence between cubic units and square units (every cube represents one square tile and vice versa), others might conceptualize the idea of measuring area incorrectly. After a long discussion, preservice teachers reached an agreement that using cubes to measure area may promote misconceptions among children. They also suggested an alternative option in Minecraft to work on 2D and other area concepts. Instead of using blocks/stones, they decided to use "carpets" with several colors to measure area of 2D shapes: "Look at this. Here are carpets. You can change the shape on the floor in red"; "Let's have students use unit carpets to cover $2 D$ shapes. They are still 2D"; "That's perfect! We solved the issue by coloring $2 D$ shapes" and so on. By using unit carpets, students can cover (change the unit color) 2D shapes and count out the colored unit squares to measure area of the shapes. Through these spontaneous conversations, preservice teachers developed their pedagogical and instructional practice knowledge based on their content knowledge.

These conversations also led preservice teachers to make connections between geometric concepts and algebraic concepts. Their reasoning resulted in the common area and volume formulas: "Let me do it. You just can cover the edges in this way"; "There's five red [carpets] in a row, and you have nine rows. Five times nine equals forty-five"; "Ta-da! Length times width"; "Make the edges of the box. Let me take a turn"; "The width is five, and the depth is four. The area of the base is twenty, and there's three layers"; "Yeah, you are seeing the formula. Length times width times height" and so on.

As illustrated above, the spontaneous mathematical discourses that were prompted by monitoring students' (peers') work provided preservice teachers with opportunities to develop their knowledge of misconceptions and difficulties that students encounter in learning mathematics. These opportunities also allowed preservice teachers to be aware of how students could help one another identify and correct misconceptions through communication and meaningful mathematical discourse recommended as effective teaching practices (NCTM, 2000, 2014) as they did. Furthermore, preservice teachers transferred their knowledge from mathematics content knowledge to mathematics pedagogical and instructional practice knowledge. Anticipating a student misconception, preservice teachers developed an instructional strategy to prevent and eliminate the student misconception and ultimately to facilitate student learning.

\subsection{Preservice Teachers' Experience and Perceptions On/Towards the Use of Minecraft}

After the preservice teachers completed the two missions (lasting roughly 40 minutes), the instructor asked them to share their feedbacks on the Minecraft activity as a class. Most preservice teachers stated the benefits of the activity in teaching and learning mathematics. "It's a super fun and interactive way to visualize and understand geometry concepts." This activity "can give students motivation to do mathematics." It "was easy to build and destroy shapes without any mess on the table." Minecraft was a "very manageable [tool] to support mathematics instructions." The preservice teachers also appreciated the value of the Minecraft activity as a formative assessment tool. According to one preservice teacher, the best thing about this activity was that "I could observe how other players were doing in the game space and I could get some ideas about how they found out the answers." This could allow teachers to "see students' understandings and misconceptions" and to give appropriate "feedback to each student in a timely manner." Many preservice teachers were excited to relate "real world uses for knowing geometry," and they also mentioned that this activity "was excellent because these activities are the virtual versions of manipulatives that I learned to teach areas and volumes."

As reviewed earlier, many educators and researchers identify various benefits of using digital games in classrooms. Preservice teachers similarly recognized the benefits of using Minecraft in teaching and learning mathematics as an effective instructional strategy, as advocated in past research findings: 1) to engage students in active learning by providing an interactive learning environment (Gee, 2007; Gros, 2007; Ke, 2008; Lacasa, 2013; Prensky, 2007; Rideout \& Saphir, 2013); 2) to give students motivation and increase student interest (Chan et al., 2017; Groff et al., 2010; Groff et al., 2015; Hsu et al., 2017; Sung et al, 2017); and 3) to provide an alternative representation for visualizing mathematical concepts (Protopsaltis et al., 2011). In this study, preservice teachers further recognized the benefits of using Minecraft as not only virtual manipulatives to support student learning but also formative assessment tools to monitor students' understanding and misconceptions that are beneficial, confirmed as an important aspect of 
computer-based manipulatives (Reimer \& Moyer, 2005). The following section demonstrates how preservice teachers could apply the benefits of using Minecraft in teaching and learning mathematics that they were aware to their future instructional practices.

\subsection{Preservice Teachers' Pedagogical and Instructional Practice Knowledge Development}

After the competition activities, the preservice teachers were asked to create a rectangular prism with a volume of 24 cubic units. They created various rectangular prisms by multiplying different numbers of unit blocks for the bases and heights $(B \times h)$, such as $24 \times 1,12 \times 2,8 \times 3$, and $6 \times 4$ (see Figure 5$)$.

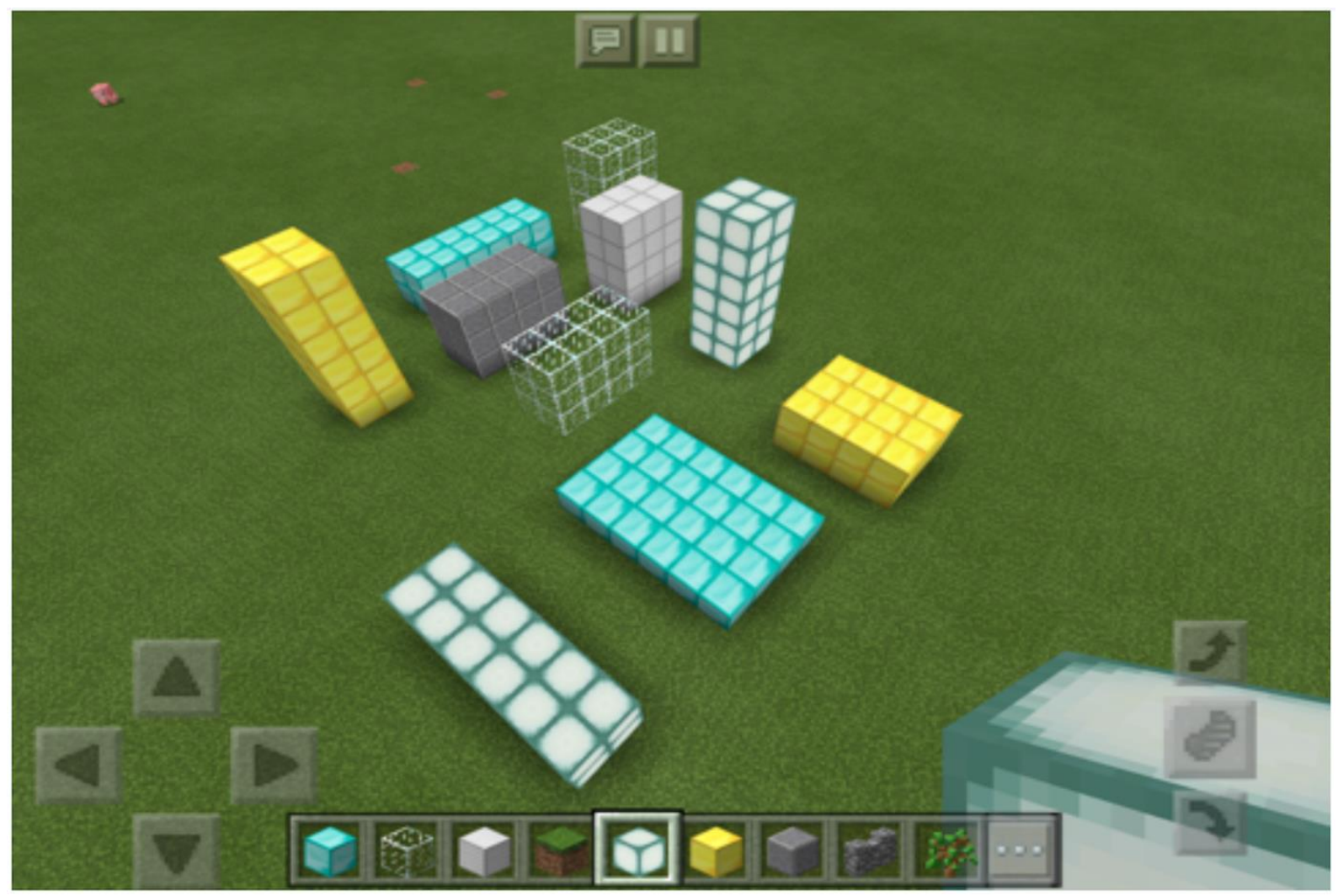

Figure 5. Rectangular prims with 24 cubic units

Preservice teachers then compared their rectangular prisms and discussed why shapes were different from each other. Their discussion focused on the common volume formula, "Area of the base $\times$ Height" or "Length $\times$ Width $\times$ Height." It led to a critical understanding of the commutative and associative properties of multiplication. They used the formula to explain why they had different shapes with the same volume. They connected geometric concepts and algebraic concepts in their spontaneous discussion. The preservice teachers generalized that changing the order of factors or groups of factors does not change the product, such as $(2 \times 3) \times 4=(3 \times 2) \times 4$ and $(2 \times 3) \times 4=2 \times(3 \times 4)$.

Finally, a preservice teacher extended the discussion to the commutative and associative properties of addition: "You can visualize the properties of addition too. Let me show you guys." She built two shapes side by side using different color blocks (see Figure 6) in order to illustrate the commutative property of addition, "Flipping the shape upside down made no change in the numbers of blocks," and the associative property of addition, "The only difference is the color of the blocks in the middle row. There is no change in the numbers of blocks." She supplemented her illustrations with symbolic representations, $2+3=3+2$ and $(2+3)+5=2+(3+5)$ respectively. 

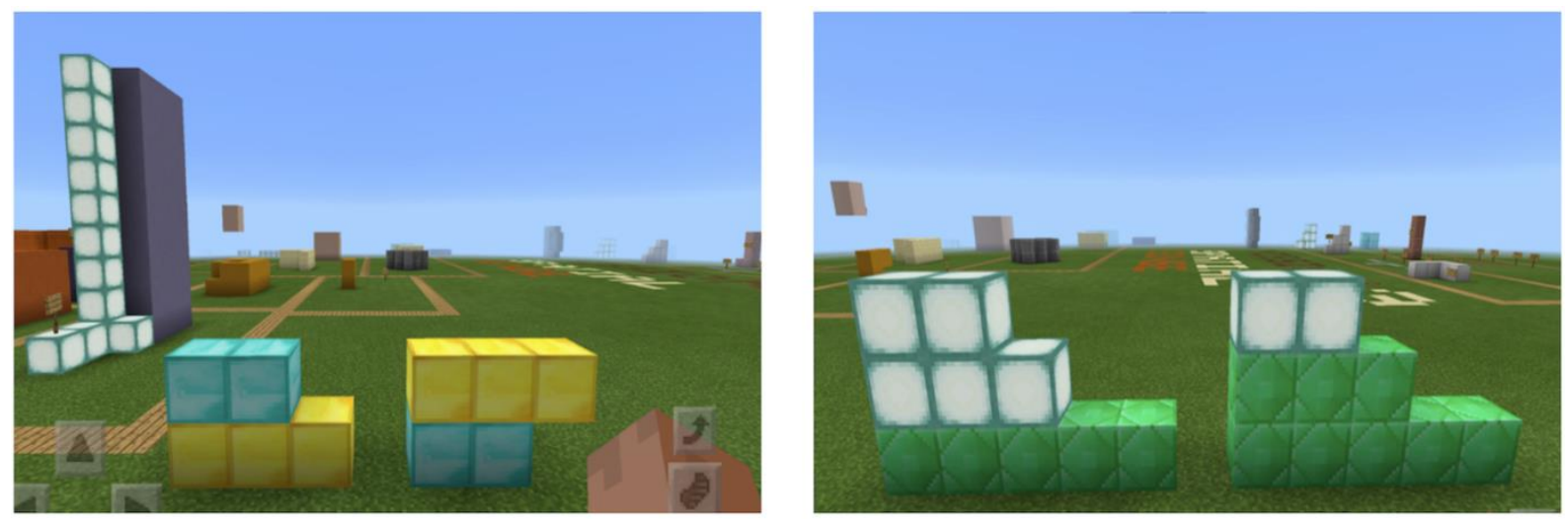

Figure 6. The commutative and associative properties of addition

In the virtual world created by Minecraft, preservice teachers visualized and discussed the commutative and associative properties of multiplication among themselves through connecting between geometric concepts and algebraic concepts. They also extended their discussion to the commutative and associative properties of addition by visualizing the concepts with their own examples. By utilizing Minecraft as an alternative representation and virtual manipulatives for visualizing mathematical concepts, preservice teachers developed their math-focused, pedagogical and instructional practice knowledge, which is necessary to effectively support all students at different levels of achievement in mathematics (Forzani, 2014), beyond mathematics content knowledge.

\section{Conclusion}

This study was designed to engage preservice teachers to learn and teach mathematics with digital games as a technology integration into classrooms. The findings from this study suggest that the experiences of preservice teachers participating in a digital game Minecraft-based activity that is integrated to a mathematics curriculum based on the geometry concepts of area and volume enabled them to not only identify potential benefits of the Minecraft activity as a useful instructional strategy for learning and teaching mathematics but also develop math-focused, pedagogical and instructional practice knowledge to effectively facilitate student learning.

The preservice teachers appreciated the usefulness and effectiveness of the Minecraft activity to enhance the teaching and learning of mathematics. They demonstrated the benefits of the virtual world in exploring the concepts of area and volume. In particular, the preservice teachers emphasized that the Minecraft activity allowed them to engage in the learning process by forcing them to interact with dynamic objects. It also allowed them to visualize the concepts themselves and to formalize the common area and volume formulas through critical reasoning. The experience as learners participating in the Minecraft activity also provided the preservice teachers with opportunities to develop math-focused instructional practice knowledge as well as knowledge of students as mathematics learners. The preservice teachers identified how the use of technology could be integrated into a formative assessment task, allowing them to explore students' understandings and misconceptions.

Finally, the preservice teachers' spontaneous discussions led to sharing ideas for potential task extensions. They considered using Minecraft for a range of simple activities with numbers and operations - such as addition, subtraction, multiplication, and division of whole numbers - to advanced activities for geometric and algebraic thinking — such as finding the maximum area of a rectangle with a given perimeter or the maximum volume of a rectangular prism with a given surface area. Thus, the Minecraft activity gave the preservice teachers an opportunity for professional growth, thinking about how to use virtual manipulatives with their own students in the near future.

This study suggests that researchers and educators need to keep an eye on alternatives that can address the identified barriers to the use of digital games in education to utilize their powerful potentials as instructional tools and assessment tools in K-12 education and teacher preparation programs. For example, further research is needed to understand how to design a digital game-based activity being aligned with teaching and learning goals within an existing curriculum.

Although this article focuses on preservice teachers' perspectives on the Minecraft activity, we believe that technology integration using Minecraft will be beneficial for students alike. It provides students with an interactive learning environment in which they have opportunities to develop their conceptual understandings of area and volume through visualizing the concepts and connecting geometry with algebra. Thus, this also provides opportunities for future research, such as a teaching experiment design research or action research to explore the influence of the Minecraft activity on student understanding and achievement in mathematics. 


\section{References}

Association of Mathematics Teacher Educators. (2017). Standards for preparing teachers of mathematics. Retrieved from https://amte.net/sites/default/files/SPTM.pdf

Bellotti, F., Berta, R., Gloria, A. D., \& Primavera, L. (2009). Enhancing the educational value of video games. ACM Computers in Entertainment, 7(2), 23-41. https://doi.org/10.1145/1541895.1541903

Bogdan, R., \& Biklen, S. (2003). Qualitative research for education: An introduction to theory and methods (4th ed.). Needham Heights, MA: Allyn \& Bacon.

Bos, B., Wilder, L., Cook, M., \& O'Donnell, R. (2014). Learning mathematics through Minecraft. Teaching Children Mathematics, 21(1), 56-59. https://doi.org/10.5951/teacchilmath.21.1.0056

Burns, B. A., \& Hamm, E. M. (2011). A comparison of concrete and virtual manipulative use in third-and fourth-grade mathematics. School Science and Mathematics, 111(6), 256-261.

https://doi.org/10.1111/j.1949-8594.2011.00086.x

Chan, K. Y. G., Tan, S. L., Hew, K. F. T., Koh, B. G., Lim, L. S., \& Yong, J. C. (2017). Knowledge for games, games for knowledge: Designing a digital roll-and-move board game for a law of torts class. Research and Practice in Technology Enhanced Learning, 12(1), 7. https://doi.org/10.1186/s41039-016-0045-1

Common Core State Standards Initiative. (2010). Common core state standards for mathematics (CCSSM). Washington, DC: National Governors Association Center for Best Practices and the Council of Chief State School Officers. Retrieved from http://www.corestandards.org/wp-content/uploads/Math_Standards.pdf

Corbin, J., \& Strauss, A. (2008). Basics of qualitative research (3rd ed). Thousand Oaks, CA: Sage.

Cordova, D. I., \& Lepper, M. R. (1993). Intrinsic motivation and the process of learning: Beneficial effects of contextualization, personalization and choice. Journal of Educational Psychology, 88(4), 715-730. https://doi.org/10.1037/0022-0663.88.4.715

Creswell, J. W. (2013). Qualitative inquiry \& research design: Choosing among five approaches. Los Angeles, CA: Sage.

Cruz, S., Carvalho, A. A. A., \& Araújo, I. (2016). A game for learning history on mobile devices. Education and Information Technologies, 22(2), 515-531. https://doi.org/10.1007/s10639-016-9491-z

De Grove, F., Bourgonjon, J., \& Van Looy, J. (2012). Digital games in the classroom? A contextual approach to teachers' adoption intention of digital games in formal education. Computers in Human Behavior, 28(6), 2023-2033. https://doi.org/10.1016/j.chb.2012.05.021

Forzani, F. M. (2014). Understanding "core practices" and "practice-based" teacher education: Learning from the past. Journal of Teacher Education, 65(4), 357-368. https://doi.org/10.1177/0022487114533800

Gee, J. P. (2004). Learning by design: Games as learning machines. Digital Education Review, 2(1), 5-16.

Gee, J. P. (2007). What video games have to teach us about learning and literacy. New York, NY: Palgrave Macmillian.

Groff, J., Howells, C., \& Cranmer, S. (2010). The Impact of console games in the classroom: Evidence from schools in Scotland. Futurelab, UK.

Groff, J., McCall, J., Darvasi, P., \& Gilbert, Z. (2015). Using games in the classroom. In K. Schoenfield (Ed.), Learning, education and games Vol. 2: Bringing games into educational contexts (pp. 19-41). Pittsburgh, PA: ETC Press.

Gros, B. (2007). Digital games in education: The design of games-based learning environments. Journal of Research on Technology in Education, 40(1), 23-28. https://doi.org/10.1080/15391523.2007.10782494

Hansen, D. S., \& Storjord, D. (2016). Learning through a game-exploring fun and learning in a project management game (Master's thesis). Available from [online] https://brage.bibsys.no/xmlui/handle/11250/2411523

Hsu, C. Y., Tsai, M. J., Chang, Y. H., \& Liang, J. C. (2017). Surveying in-service teachers' beliefs about game-based learning and perceptions of technological pedagogical and content knowledge of games. Educational Technology and Society, 20(1), 134-143.

Huizenga, J. C., Ten Dam, G. T. M., Voogt, J. M., \& Admiraal, W. F. (2017). Teacher perceptions of the value of game-based learning in secondary education. Computers and Education, 110, 105-115. https://doi.org/10.1016/j.compedu.2017.03.008

Judge, S., Floyd, K., \& Jeffs, T. (2015). Using mobile media devices and apps to promote young children's learning. In K. L. Heider \& M. R. Jalongo (Eds.), Young children and families in the information age, educating the young 
child (pp. 117-131). New York, NY: Springer. https://doi.org/10.1007/978-94-017-9184-7_7

Justice, L. J., \& Ritzhaupt, A. D. (2015). Identifying the barriers to games and simulations in education: Creating a valid and reliable survey. Journal of Educational Technology Systems, 44(1), 86-125. https://doi.org/10.1177/0047239515588161

Ke, F. (2008). A case study of computer gaming for math: Engaged learning from gameplay? Computers and Education, 51(4), 1609-1620. https://doi.org/10.1016/j.compedu.2008.03.003

Kirriemuir, J., \& McFarlane, A. E. (2004). Literature review in games and learning. Bristol: Futurelab.

Lacasa, P. (2013). Learning in real and virtual worlds: Commercial video games as educational tools. New York, NY: Palgrave Macmillian. https://doi.org/10.1057/9781137312051

McFarlane, A., Sparrowhawk, A., \& Heald, Y. (2002). Report on the educational use of games. An exploration by TEEM of the contribution which games can make to the education process. London: DfES.

Miles, M. B., \& Huberman, A. M. (1994). Qualitative data analysis. Thousand Oaks, CA: Sage.

Minecraft Teachers. (2015). Welcome to the Google Group dedicated to helping teachers use Minecraft to facilitate learning [Online group]. Retrieved from https://groups.google.com/forum/\#!forum/minecraft-teachers

Moyer-Packenham, P., Niezgoda, D., \& Stanley, J. (2005). Young children's use of virtual manipulatives and other forms of mathematical representations. In W. J. Masalski \& P. C. Elliott (Eds.), Technology-supported mathematics learning environments: Sixty-seventh yearbook (pp. 17-34). Reston, VA: National Council of Teachers of Mathematics.

Nancy, B. S., \& Roberta, D. (2009). Teacher candidates' views of digital games as learning devices. Issues in Teacher Education, 18(2), 47-67.

National Council of Teachers of Mathematics. (2000). Principles and standards for school mathematics. Reston, VA: NCTM.

National Council of Teachers of Mathematics. (2014). Principles to actions: Ensuring mathematical success for all. Reston, VA: NCTM.

Papadakis, S. (2018). The use of computer games in classroom environment. International Journal of Teaching and Case Studies, 9(1), 1-25. https://doi.org/10.1504/IJTCS.2018.090191

Papadakis, S., \& Kalogiannakis, M. (2017). Mobile educational applications for children: What educators and parents need to know. International Journal of Mobile Learning and Organisation, 11(3), 256-277. https://doi.org/10.1504/IJMLO.2017.085338

Papanastasiou, G. P., Drigas, A. S., \& Skianis, C. (2017). Serious games in preschool and primary education: Benefits and impacts on curriculum course syllabus. International Journal of Emerging Technologies in Learning, 12(1), 44-56. https://doi.org/10.3991/ijet.v12i01.6065

Prensky, M. (2007). Digital game-based learning. Saint Paul, MN: Paragon House.

Protopsaltis, A., Panesse, L., Pappa, D., \& Hetzner, S. (2011). Serious games and formal and informal learning. eLearning Papers, 25, 1-10.

Rallis, S. F., \& Rossman, G. B. (2012). The research journey: Introduction to inquiry. New York, NY: The Guilford Press.

Reimer, K., \& Moyer-Packenham, P. S. (2005). Third-graders learn about fractions using virtual manipulatives: a classroom study. Journal of Computers in Mathematics and Science Teaching, 24(1), 5-25.

Rice, J. W. (2007a). New media resistance: Barriers to implementation of computer video games in the classroom. Journal of Educational Multimedia and Hypermedia, 16(3), 249-261.

Rice, J. W. (2007b). Assessing higher order thinking in video games. Journal of Technology and Teacher Education, 15(1), 87-100.

Rideout, V., \& Saphir, M. (2013). Zero to eight: Children's media use in America 2013. San Francisco, CA: Common Sense Media.

Short, D. (2012). Teaching scientific concepts using a virtual world--Minecraft. Teaching Science, 58(3), 55-58.

Silverstein, G., Frechtling, J., \& Miyaoka, A. (2000). Evaluation of the use of technology in Illinois Public Schools: Final report. Rockville, MD: Westat. 
Sonja, G. (2016). Why digital game based learning should be included in teacher education. Reflecting Education, 10(1), 26-38.

Sung, H. Y., \& Hwang, G. J. (2013). A collaborative game-based learning approach to improving students' learning performance in science courses. Computers and Education, 63, 43-51. https://doi.org/10.1016/j.compedu.2012.11.019

Sung, H. Y., Hwang, G. J., Lin, C. J., \& Hong, T. W. (2017). Experiencing the Analects of Confucius: An experiential game-based learning approach to promoting students' motivation and conception of learning. Computers and Education, 110, 143-153. https://doi.org/10.1016/j.compedu.2017.03.014

Van Eck, R. (2006). Digital game-based learning: It's not just the digital natives who are restless. EDUCAUSE Review, $41(2), 16-30$.

Yin, R. K. (2013). Case study research: Design and methods (5th ed.). Los Angeles, CA: Sage.

\section{Copyrights}

Copyright for this article is retained by the author(s), with first publication rights granted to the journal.

This is an open-access article distributed under the terms and conditions of the Creative Commons Attribution license which permits unrestricted use, distribution, and reproduction in any medium, provided the original work is properly cited. 